\title{
Anti-inflammatory effects of sargachromenol-rich ethanolic extract of Myagropsis myagroides on lipopolysaccharide-stimulated BV-2 cells
}

\author{
Sunghee Kim¹, Min-Sup Lee ${ }^{1,4}$, Bonggi Lee², Wi-Gyeong Gwon ${ }^{1}$, Eun-Ji Joung ${ }^{1}$, Na-Young Yoon ${ }^{3}$
} and Hyeung-Rak Kim ${ }^{\text {** }}$

\begin{abstract}
Background: Excessive pro-inflammatory cytokine production from activated microglia contributes to neurodegenerative diseases, thus, microglial inactivation may delay the progress of neurodegeneration by attenuating the neuroinflammation. Among 5 selected brown algae, we found the highest antioxidant and anti-neuroinflammatory activities from Myagropsis myagroides ethanolic extract (MME) in lipopolysaccharide (LPS)-stimulated BV-2 cells.

Methods: The levels of nitric oxide (NO), prostaglandin $\mathrm{E}_{2}\left(\mathrm{PGE}_{2}\right)$, and pro-inflammatory cytokines were measured by Griess assay and enzyme linked immunesorbent assay. The levels of inducible nitric oxide synthase (iNOS),

cyclooxygenase-2 (COX-2), mitogen-activated protein kinases (MAPKs), and Akt were measured using Western blot. Nuclear translocation and transcriptional activation of nuclear factor-KB (NF-KB) were determined by immunefluorescence and reporter gene assay, respectively.

Results: MME inhibited the expression of iNOS and COX-2 at mRNA and protein levels, resulting in reduction of NO and $\mathrm{PGE}_{2}$ production. As a result, pro-inflammatory cytokines were reduced by MME. MME also inhibited the activation and translocation of NF-KB by preventing inhibitor KB-a (IKB-a) degradation. Moreover, MME inhibited the phosphorylation of extracellular signal regulated kinases (ERKs) and c-Jun N-terminal kinases (JNKs). Main anti-inflammatory compound in MME was identified as sargachromenol by NMR spectroscopy.
\end{abstract}

Conclusions: These results indicate that the anti-inflammatory effect of sargachromenol-rich MME on LPS-stimulated microglia is mainly regulated by the inhibition of IKB-a/NF-KB and ERK/JNK pathways.

Keywords: Myagropsis myagroides, Sargachromenol, Pro-inflammatory cytokine, Microglia, Nuclear factor-KB, Neuroinflammation

\section{Background}

Microglia, a macrophage-like cells in the brain, play a pivotal role in the innate immune response in the central nervous system. Microglia are activated by the broad spectrum of stimuli such as lipopolysaccharide (LPS), interferon- $\gamma$, or $\beta$-amyloid [1,2]. Activated microglia produce various neurotoxic factors including inflammatory mediators such as nitric oxide $(\mathrm{NO})$ and prostaglandin $\mathrm{E}_{2}$ $\left(\mathrm{PGE}_{2}\right)$, and pro-inflammatory cytokines such as tumor necrosis factor- $\alpha$ (TNF- $\alpha$ ), interleukin (IL)-1 $\beta$, and IL-6

\footnotetext{
* Correspondence: hrkim@pknu.ac.kr

${ }^{1}$ Department of Food Science and Nutrition, Pukyong National University, Yongso-ro, Nam-gu, Busan 608-737, South Korea

Full list of author information is available at the end of the article
}

$[3,4]$. Pathogenic roles of inflammatory mediators and cytokines have been implicated in various inflammatory and neurodegenerative diseases, including Alzheimer's disease, Parkinson's disease, trauma, multiple sclerosis, and cerebral ischemia $[5,6]$.Therefore, the modulation of microglial activation is important for the prevention or relief of neuroinflammation.

The induction of inflammatory proteins and proinflammatory cytokines are primarily controlled at transcriptional level [7]. Transcriptional induction of inducible nitric oxide synthase (iNOS) and cyclooxygenase-2 (COX2 ) is largely dependent on cooperative activities of multiple transcription factors, including nuclear factor- $\kappa B$ $(\mathrm{NF}-\mathrm{kB})$ and activator protein 1 which act on cognate 
cis-acting elements in the iNOS or COX-2 promoter $[7,8]$. NF- $\kappa B$ plays key roles in early stage of immune and inflammatory responses as well as cell survival $[9,10]$. In unstimulated conditions, NF- $\mathrm{kB}$ bound with inhibitory kappaB- $\alpha(\mathrm{I} \kappa \mathrm{B}-\alpha)$ is located in the cytoplasm as an inactive complex. Exposure to LPS stimulates phosphorylation, ubiquitination, and degradation of I $\mathrm{B}-\alpha$, resulting in nuclear translocation of NF- $\kappa \mathrm{B}$ by dissociation of NF-kB-ІкB- $\alpha$ complex for the transcription of target genes [11]. The activation of NF- $\mathrm{KB}$ is also regulated by cellular kinases such as mitogenactivated protein kinases (MAPKs) [12]. The MAPKs such as extracellular signal-regulated kinase (ERK), p38 MAPK, and c-Jun $\mathrm{NH}_{2}$-terminal kinase (JNK) have been involved in the transcriptional regulations of inflammatory genes $[12,13]$.

Marine macroalgae have been used as a healthy diet in East Asia for centuries. Recently, various studies revealed that their constituents such as phlorotannins and pigments showed diverse biological activities including antioxidation [14-16] and anti-inflammation [15,17-20]. Myagropsis myagroides, growing subtidal zone of the coast of East Asia, belongs to the family Sargassaceae in Phaeophyta. It shows the anti-inflammatory activity and its active compound was tentatively identified as phlorofucofuroeckol B by NMR spectroscopy and 6,6'-bieckol $[21,22]$. However, we found that $M$. myagroides ethanolic extract (MME) showed higher anti-inflammatory activity than phlorofucofuroeckol B and 6,6'-bieckol and the isolated compound was identified as sargachromenol. Biological activities of sargachromenol were limited to anti-photoaging activity [23], anti-cholinesterase activity [24], and neuronal growth factor [25]. To our knowledge, no previous study has been reported on the anti-inflammatory activity of sargachromenol-rich MME in LPS-treated BV-2 cells. BV-2 cells, derived from primary mouse microglia cells, are considered as a reasonable model for in vitro pharmacological studies, since their response to LPS showed a similar pattern to primary microglia in vivo based on transcriptome and proteome analysis [26]. With respective to neurodegeneration studies, activated BV-2 cells by LPS secret pro-inflammatory cytokines, which have been shown to promote neuronal injury at high level [27]. This led us to evaluate the inhibitory effect of MME on inflammation using BV-2 cells, and we further investigated the possible molecular mechanisms underlying its anti-inflammatory action on cultured BV-2 cells.

\section{Methods}

Algae materials and preparation of ethanolic extracts Myagropsis myagroides (MBRB0078-TC10499), Undaria pinnatifida (MBRB0049-TC9322), Saccharina japonica (MBRM0094-TC11278), Sargassum horneri (MBRB0037-
TC9244), and S. fulvellum (MBRB00112-TC7337) were collected along the coast of Busan, South Korea from January to August 2012. Taxonomic identification of the collected seaweeds was authenticated by an agal taxonomist (C.G. Choi), at the Department of Ecological Engineering, Pukyong National University, South Korea. Voucher specimens were deposited in the Marine Brown Algae Resources Bank, South Korea. The collected seaweeds were sun-dried for 3 days and ground with hammer mill. Each dried powder (100 g) was extracted three times with $500 \mathrm{~mL}$ of ethanol $(95 \%, \mathrm{v} / \mathrm{v})$ for $3 \mathrm{~h}$ at $70^{\circ} \mathrm{C}$. The combined extracts were concentrated using a rotary vacuum evaporator (Eyela, Tokyo, Japan) at $40^{\circ} \mathrm{C}$ and lyophilized to obtain the ethanolic extracts of seaweed.

\section{Chemicals}

Cell culture medium and all the other materials required for cell culture were purchased from Gibco BRL Life Technologies (Grand Island, NY, USA). LPS (Escherichia coli O55:B5), dimethyl sulfoxide (DMSO), bovine serum albumin (BSA), and the specific protein kinase inhibitors (PD98059 and SP600125) were purchased from Sigma Chemical Co. (St. Louis, MO, USA). CellTiter ${ }^{96}$ AQueous One Solution Cell Proliferation assay kit, dual-luciferase assay system, murine NF- $\mathrm{kB}$ promoter/luciferase DNA, pRL-TK DNA, and moloney murine leukemia virus (M-MLV) reverse transcriptase were obtained from Promega (Madison, WI, USA). Enzyme-linked immunosorbent assay (ELISA) kits for TNF- $\alpha$, IL- $1 \beta$, and IL-6 were obtained from eBioscience (San Diego, CA, USA) and $\mathrm{PGE}_{2}$ ELISA kit was purchased from R\&D Systems (Minneapolis, MN, USA). Primary and secondary antibodies were purchased from Cell Signaling Biotechnology (Danvers, MA, USA) and Santa Cruz Biotechnology (Santa Cruz, CA, USA), respectively. 4,6-Diamidino-2phenylindole (DAPI), Lipofectamine Plus Reagent, TRIzol, and Alexa Fluor ${ }^{\bullet}$ 488-conjugated secondary antibody were purchased from Invitrogen (Carlsbad, CA, USA). The enhanced chemiluminescence (ECL) detection kit was purchased from GE Healthcare Life Sciences (Piscataway, NJ, USA).

\section{Measurement of total phenolic content}

Total phenolic content was measured according to the method of Koivikko et al. (2005) [28]. In brief, diluted sample $0.5 \mathrm{~mL}$ was mixed with $0.5 \mathrm{~mL}$ of $1 \mathrm{~N}$ FolinCiacalteu solution and incubated at $37^{\circ} \mathrm{C}$. After $5 \mathrm{~min}$, $1.0 \mathrm{~mL}$ of $20 \%$ sodium carbonate was added and the mixture was incubated for $30 \mathrm{~min}$. The absorbance was measured at $730 \mathrm{~nm}$, and total phenolic content was calculated using a phloroglucinol (Sigma Chemical Co.) as a standard. 


\section{Cell culture and viability assay}

Murine BV-2 microglial cell lines were maintained in Dulbecco's Modified Eagle's Medium (DMEM) supplemented with $10 \%$ fetal bovine serum (FBS), penicillin (100 units $/ \mathrm{mL})$, and streptomycin sulfate $(100 \mu \mathrm{g} / \mathrm{mL})$ in a humidified atmosphere of $5 \% \mathrm{CO}_{2}$. Cell viability was determined by 3-(4,5-dimethylthiazol-2-yl)-5-(3-carboxymethoxyphenyl)-2-(4-sulfophenyl)-2H-tetrazolium (MTS) assay using CellTiter ${ }^{96} \mathrm{AQ}_{\text {ueous }}$ One Solution Cell Proliferation assay kit according to the manufacturer's manual. Cells were inoculated at a density of $3 \times 10^{5}$ cells into 96-well plates and cultured at $37^{\circ} \mathrm{C}$ for $24 \mathrm{~h}$. Cells were then treated with LPS $(1 \mu \mathrm{g} / \mathrm{mL})$ in the presence or absence of MME in different concentration for $24 \mathrm{~h}$. The final concentration of DMSO was less than $0.1 \%$ in the cell culture medium. The culture medium was removed and replaced by $95 \mu \mathrm{L}$ of fresh culture medium and $5 \mu \mathrm{L}$ of MTS solution. After $1 \mathrm{~h}$, the absorbance at $490 \mathrm{~nm}$ was measured using a microplate reader (Glomax Multi Detection System, Promega).

\section{Measurement of intracellular ROS}

The intracellular ROS scavenging activity of the sample was measured using the fluorescent probe 2'7'-dichlorodihydrofluorescin diacetate (DCFH-DA). The cells were incubated with different concentrations of extracts in the absence or presence of LPS $(1 \mu \mathrm{g} / \mathrm{mL})$ for $2 \mathrm{~h}$. Harvested cells by trypsin-EDTA solution [0.05\% trypsin and $0.02 \%$ EDTA in phosphate buffered saline (PBS)] were washed twice with PBS and treated with $20 \mu \mathrm{M}$ $\mathrm{DCFH}-\mathrm{DA}$ for $30 \mathrm{~min}$ at $37^{\circ} \mathrm{C}$. The fluorescence intensity was measured at excitation wavelength of $485 \mathrm{~nm}$ and emission wavelength of $528 \mathrm{~nm}$ using a fluorescence microplate reader (Dual Scanning SPECTRAmax, Molecular Devices Co., Sunnyvale, CA, USA). Relative ROS level was adjusted with protein concentration of cell lysates by BCA protein assay (Pierce Biotechnology, Rockford, IL, USA).

\section{Measurements of $\mathrm{NO}, \mathrm{PGE}_{2}$ and pro-inflammatory cytokines}

Cells $\left(5 \times 10^{4}\right.$ cells/well $)$ were pretreated with MME $(0-25 \mu \mathrm{g} / \mathrm{mL})$ for $2 \mathrm{~h}$ prior to LPS treatment for $24 \mathrm{~h}$. After treatment of LPS, cultured media of BV-2 cells were collected and stored at $-72^{\circ} \mathrm{C}$ until tested. For the measurement of NO, $100 \mu \mathrm{L}$ of culture supernatant was mixed with the same volume of Griess reagent $(0.1 \%$ naphthylethylenediamine dihydrochloride and $1 \%$ sulfanilamide in 5\% phosphoric acid) and incubated at room temperature for $10 \mathrm{~min}$. Absorbance of the mixture was measured with a microplate reader at $540 \mathrm{~nm}$. Levels of PGE 2 , TNF- $\alpha$, IL-1 $\beta$, and IL-6 in culture media from each group were quantitatively determined by ELISA kit according to the manufacturer's instructions.

\section{Western blot analysis}

Proteins $(30 \mu \mathrm{g})$ were separated by sodium dodecyl sulfate-polyacrylamide gel electrophoresis and transferred onto the nitrocellulose membranes. The membranes were washed with Tris-buffered saline (10 mM Tris- $\mathrm{HCl}, 150 \mathrm{mM} \mathrm{NaCl}, \mathrm{pH}$ 7.5) supplemented with $0.05 \%$ Tween 20 (TBST) followed by blocking with TBST containing 5\% non-fat dried milk. The membranes were incubated overnight with primary antibodies. After washing three times with TBST, the membranes were then exposed to secondary antibodies coupled to horseradish peroxidase for $2 \mathrm{~h}$ at room temperature. The membranes were washed three times with TBST at room temperature. Immunoreactivities were detected by ECL reagents. Densitometric analysis of the data obtained from at least three independent experiments was performed using cooled CCD camera system EZ-Capture II (ATTO \& Rise Co., Tokyo, Japan) and CS analyzer ver. 3.00 software (ATTO \& Rise Co.).

\section{Reverse transcription-polymerase chain reaction (RT-PCR)}

BV-2 cells plated in a 6-well cell culture plate at a density of $3.0 \times 10^{5}$ cells/well were pretreated without or with MME for $2 \mathrm{~h}$ and then treated with LPS for $6 \mathrm{~h}$. Total RNA from each group was isolated with the TRIzol reagent. Five micrograms of total RNA was used for reverse transcription using oligo-dT and M-MLV reverse transcriptase. PCR was carried out using the resulting cDNA as a template, with the following condition: 25 cycles of denaturation at $95^{\circ} \mathrm{C}$ for $30 \mathrm{~s}$, annealing at $60^{\circ} \mathrm{C}$ for $30 \mathrm{~s}$, and extension at $72^{\circ} \mathrm{C}$ for $30 \mathrm{~s}$. Verification of PCR product of specific genes was established by their predicted sizes under ultraviolet light illuminator. The primer sequences were following: 5'-ACC ACT CGT ACT TGG GAT GC-3' (sense), 5'-CAC CTT GGA GTT CAC CCA GT-3' (antisense) for iNOS (accession no. NM_010927); 5'TGG GCA AAG AAT GCA AAC AT-3' (sense); 5'-CAG CAA ATC CTT GCT GTT CC-3' (antisense) for COX-2 (accession no. NM_011198); 5'-GAC CCC TTC ATT GAC CTC AA-3' (sense), 5'-CTT CTC CAT GGT GGT GAA GA-3' (antisense) for glyceraldehyde 3-phosphate dehydrogenase (GAPDH) (accession no. NM_008084). GAPDH was used as an internal standard to evaluate relative expression of COX-2 and iNOS. Densitometric analysis of the data obtained from at least three independent experiments was performed using CS analyzer ver. 3.00 software.

\section{Immunofluorescence analysis}

To analyze nuclear localization of NF- $\mathrm{kB}$ in BV-2 cells, cells were cultured on glass coverslips (SPL Lifesciences Co., Gyeonggi-do, Korea) in 24-well plates for $24 \mathrm{~h}$. After preincubation with MME for $2 \mathrm{~h}$, cells were stimulated with or without LPS $(1 \mu \mathrm{g} / \mathrm{mL})$ for $30 \mathrm{~min}$. Cells were fixed in $4.0 \%$ paraformaldehyde in PBS for $15 \mathrm{~min}$ 
at room temperature, and then permeabilized with $0.5 \%$ Triton X-100 in PBS for 10 min. Permeabilized cells were washed with PBS and blocked with $3 \%$ BSA in PBS for $30 \mathrm{~min}$. Thereafter, cells were incubated in an antiNF- $\mathrm{BB}$ monoclonal antibody diluted in 3\% BSA/PBS for $2 \mathrm{~h}$, rinsed three times for $5 \mathrm{~min}$ with $\mathrm{PBS}$, and incubated in Alexa Fluor ${ }^{\ominus}$ 488-conjugated secondary antibody diluted in 3\% BSA/PBS for $1 \mathrm{~h}$. Cells were stained with $2 \mu \mathrm{g} / \mathrm{mL}$ DAPI and viewed, and images were captured using an LSM700 laser scanning confocal microscope (Carl Zeiss, Oberkochen, Germany).

\section{Preparation of cytosolic and nuclear extracts}

BV-2 cells plated in a 6 -well cell culture plates at a density of $1 \times 10^{6}$ cells per well were pretreated with or without MME for $2 \mathrm{~h}$ and then treated with LPS for $0.5 \mathrm{~h}$. Cells were washed twice with ice-cold PBS, scraped in PBS and centrifuged at $13,000 \mathrm{~g}$ for $5 \mathrm{~min}$ at $4^{\circ} \mathrm{C}$. Pellets were suspended in $180 \mu \mathrm{L}$ of hypotonic buffer $\mathrm{A}$ [10 mM Tris-HCl (pH 7.4), $10 \mathrm{mM} \mathrm{NaCl,} 3 \mathrm{mM}$ $\mathrm{MgCl}_{2}, 0.02 \% \mathrm{NaN}_{3}, 0.5 \mathrm{mM}$ DTT and $1 \mathrm{mM}$ PMSF] on ice, and afterward, $20 \mu \mathrm{L}$ of $5 \%$ Nonidet P-40 was added for $5 \mathrm{~min}$. The mixture was centrifuged at $1,800 \mathrm{~g}$ for $5 \mathrm{~min}$. Supernatant was collected as cytosolic extract. The pellets were washed with hypotonic buffer and resuspended in hypertonic buffer C [20 mM 4(2-hydroxyethyl)-1-piperazineethanesulfonic acid ( $\mathrm{pH} 7.4$ ), 25\% glycerol, $420 \mathrm{mM} \mathrm{NaCl}, 1.5 \mathrm{mM} \mathrm{MgCl}_{2}, 0.2 \mathrm{mM}$ EDTA, $0.02 \% \mathrm{NaN}_{3}, 0.5 \mathrm{mM} \mathrm{DTT}$, and $1 \mathrm{mM} \mathrm{PMSF]} \mathrm{for}$ $1 \mathrm{~h}$ on ice and centrifuged at $14,000 \mathrm{~g}$ for $10 \mathrm{~min}$. The supernatant containing nuclear proteins was collected and stored at $-72^{\circ} \mathrm{C}$ after determination of the protein concentration.

\section{NF-kB promoter/luciferase assay}

Two micrograms of $\mathrm{pNF}-\mathrm{kB}$ promoter/luciferase DNA along with $40 \mathrm{ng}$ of control pRL-TK DNA was transiently transfected into $2.0 \times 10^{5} \mathrm{BV}-2$ microglia cells per well in a six-well plate using Lipofectamine Plus reagents for $40 \mathrm{~h}$. Cells were treated with MME for $2 \mathrm{~h}$ and stimulated with LPS $(1 \mu \mathrm{g} / \mathrm{mL})$ for $6 \mathrm{~h}$. Luciferase activities of the cells were measured using dual-luciferase assay system according to the manufacturer's instructions. Each transfection was performed in triplicate, and all experiments were repeated at least three times. The luciferase activity was normalized with luciferase activity of control pRL-TK.

\section{Isolation and identification of sargachromenol from MME} Aliquots of MME were dissolved in methanol and separated by Shimadzu high-performance liquid chromatography (HPLC) system with Luna RP-18 [Luna C18(2), $5 \mu \mathrm{m}, 250 \times 10 \mathrm{~mm}$, Phenomenex, Torrence, CA, USA]. The separation of MME was conducted using 100\% methanol (solvent A) and $0.1 \%$ formic acid in water (solvent B) as a mobile phase. The elution profile consisted of a linear gradient from A/B (78/22) to A/B (95/5) in $90 \mathrm{~min}$ and hold for $10 \mathrm{~min}$ and then re-equilibration of the column with $\mathrm{A} / \mathrm{B}(78 / 22)$ for $18 \mathrm{~min}$. The flow rate was $3.5 \mathrm{~mL} / \mathrm{min}$ at $35^{\circ} \mathrm{C}$ oven temperature and detection was performed at $270 \mathrm{~nm}$. Fractions were collected and assessed for the ability to inhibit NO secretion using LPS-stimulated BV-2 cells. The isolated compound $\left(10 \mathrm{mg}\right.$ ) was dissolved in $0.6 \mathrm{~mL}$ of $\mathrm{CDCl}_{3}$ and used for ${ }^{1} \mathrm{H}$ and ${ }^{13} \mathrm{C}$-NMR spectroscopy. NMR spectra were obtained by Fourier transform NMR JNM ECP-400 (JEOL, Tokyo, Japan). The chemical structure of the purified compound was identified by comparing its data with literature [24].

\section{Statistical analysis}

Data were expressed as the means \pm SDs of at least three independent experiments unless otherwise indicated. Data were analyzed using one-way analysis of variance (ANOVA), followed by each pair of Student's $t$-tests for multiple comparisons. Differences with a value of $p<0.05$ were considered statistically significant. All analyses were performed using SPSS for Windows, version 10.07 (SPSS, Chicago, IL, USA).

Table 1 Phenolic contents, NO and ROS suppressive activities, and yields of ethanolic extracts from the selected brown seaweeds

\begin{tabular}{lllll}
\hline & $\begin{array}{l}\text { Phenols } \\
(\mathbf{m g} / \mathbf{g})\end{array}$ & $\begin{array}{l}\mathbf{N O}^{\mathbf{1})} \\
\left.\mathbf{( E C}_{\mathbf{5 0}}, \boldsymbol{\mu g} / \mathbf{m L}\right)\end{array}$ & $\begin{array}{l}\text { ROS }^{\mathbf{2})} \\
\left(\mathrm{EC}_{\mathbf{5 0}}, \boldsymbol{\mu g} / \mathbf{m L}\right)\end{array}$ \\
\hline Myagropsis myagroides & $40.4 \pm 2.40$ & $6.84 \pm 0.78$ & $112.4 \pm 8.2$ & $15.9 \pm 2.1$ \\
Sargassum horneri & $17.6 \pm 1.48$ & $>100$ & $134.2 \pm 15.3$ & $16.0 \pm 1.1$ \\
Sargassum fulvellum & $12.1 \pm 0.71$ & $53.1 \pm 1.86$ & $402.1 \pm 34.2$ & $13.4 \pm 0.79$ \\
Undaria pinnatifida & $9.46 \pm 0.86$ & $32.9 \pm 3.24$ & $240.3 \pm 19.3$ & $8.90 \pm 0.81$ \\
Saccharina japonica & $9.61 \pm 0.03$ & $43.9 \pm 2.95$ & $208.6 \pm 16.2$ & $13.4 \pm 0.98$ \\
Sargachromenol & & $1.14 \pm 0.11$ & $8.31 \pm 0.92$ &
\end{tabular}

All values are duplicated assays \pm standard errors for three replicated extractions (i.e., $n=6$ )

$\mathrm{EC}_{50}$, half maximal effective concentration.

${ }^{1)}$ Inhibitory activity of NO production in LPS-treated BV-2 cells.

${ }^{2)}$ Inhibitory activity of ROS generation in LPS-treated BV-2 cells. 


\section{Results}

Total phenolic contents and inhibitory activities of the seaweed extracts on NO and ROS production

$M$. myagroides and S. horneri showed higher yield of ethanolic extract than the other seaweeds and $M$. myagroides showed highest phenolic contents (Table 1). Since phenolic compounds are commonly found in plants and have been reported to have diverse biological activities including antioxidant and anti-inflammatory activities, we determined inhibitory activities of ROS and NO production of the extracts. M. myagroides showed highest antioxidant activity expressed as ROS scavenging activity $\left(\mathrm{EC}_{50}, 112.4 \pm 8.2 \mu \mathrm{g} / \mathrm{mL}\right)$ and anti-inflammatory activity expressed as the inhibition of $\mathrm{NO}$ production $\left(\mathrm{EC}_{50}\right.$, $6.84 \pm 0.78 \mu \mathrm{g} / \mathrm{mL}$ ) in LPS-treated BV-2 cells. Due to strong anti-inflammatory activity and high phenolic contents, MME was chosen to investigate the antiinflammatory properties and its underlying mechanisms.

\section{MME inhibits $\mathrm{NO}$ and $\mathrm{PGE}_{2}$ production in LPS-stimulated BV-2 cells}

To evaluate the effect of MME on LPS-induced production of inflammatory mediators including $\mathrm{NO}$ and $\mathrm{PGE}_{2}$, BV-2 cells were pretreated with $0-25 \mu \mathrm{g} / \mathrm{mL}$ MME for $2 \mathrm{~h}$ and stimulated with LPS for $24 \mathrm{~h}$. NO production, measured as nitrite, was increased by LPS, however, MME significantly reduced NO levels in LPS-stimulated cells in a dose-dependent manner ( $p<0.05$, Figure $1 \mathrm{~A})$. Increased $\mathrm{PGE}_{2}$ production by LPS was also significantly suppressed by MME in a dose-dependent manner with $\mathrm{EC}_{50}$ value of $8.40 \pm 1.08 \mu \mathrm{g} / \mathrm{mL}$ (Figure $1 \mathrm{~B}$ ). To exclude the possibility that the decreased $\mathrm{NO}$ and $\mathrm{PGE}_{2}$ levels were due to cell death, cytotoxicity of MME was determined by MTS assay. The result demonstrated that MME showed no cytotoxicity in BV-2 cells up to $50 \mu \mathrm{g} / \mathrm{mL}$ (Figure 1C). Thus, the inhibitory effects of MME on $\mathrm{NO}$ and $\mathrm{PGE}_{2}$ production were not due to cytotoxicity.

\section{MME inhibits iNOS and COX-2 expressions in LPS-stimulated BV-2 cells}

To investigate whether the inhibitory effects of MME on $\mathrm{NO}$ and $\mathrm{PGE}_{2}$ production are related to the regulation of the expression of iNOS and COX-2 proteins, respectively, BV-2 cells were pretreated with the indicated concentrations of MME for $2 \mathrm{~h}$ and then stimulated with LPS $(1 \mu \mathrm{g} / \mathrm{mL})$ for $16 \mathrm{~h}$. LPS treatment induced a dramatic increase in iNOS and COX-2 proteins, as compared to the untreated control group (Figure 2A). Pretreatment of MME strongly inhibited the expression of iNOS and COX-2 proteins in a dose-dependent manner $(p<0.05)$. In addition to protein expression, MME inhibited iNOS and COX-2 mRNA expression in a dose-dependent manner in LPS-stimulated BV-2 cells $(p<0.05$ Figure 2B). These results suggest that MME-mediated inhibition of
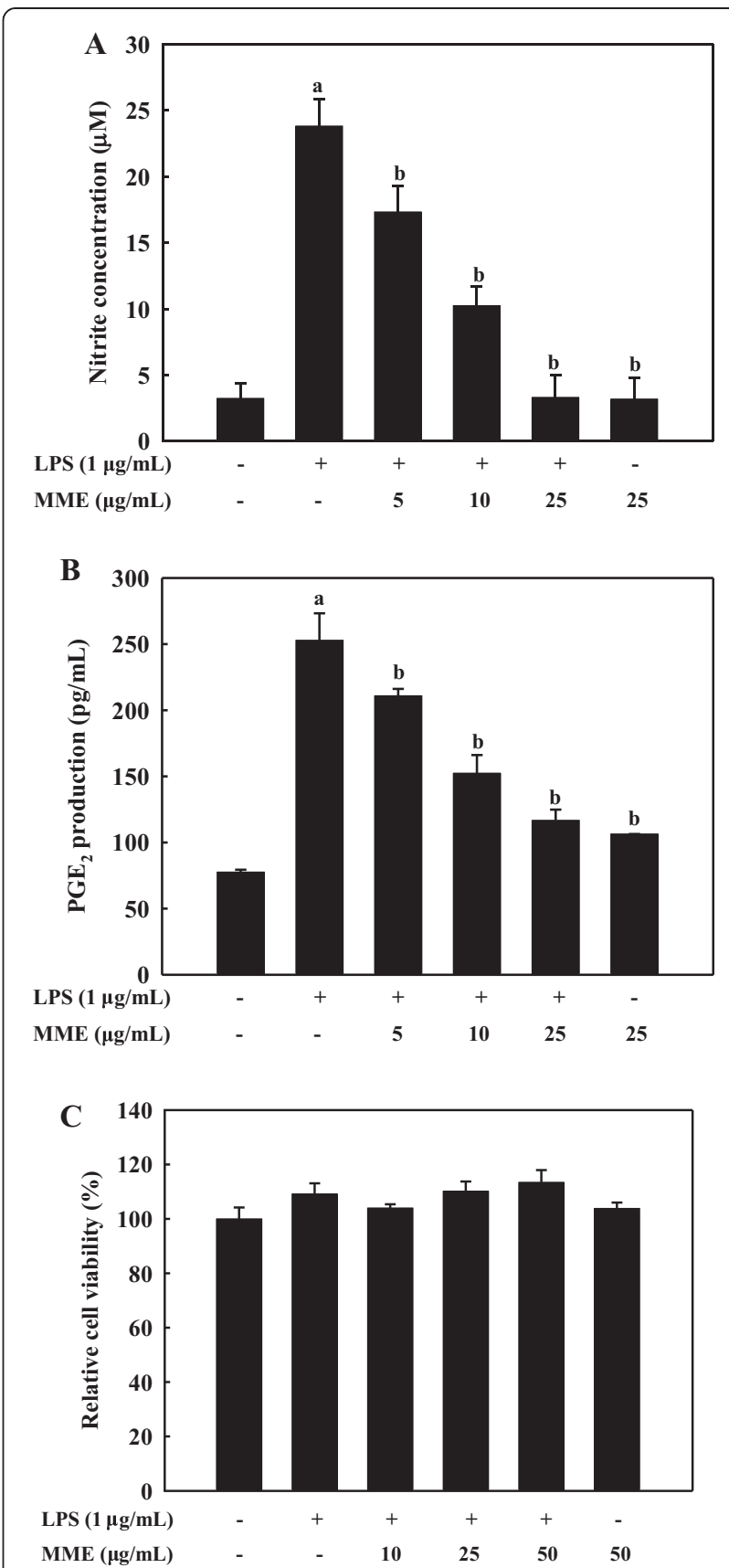

Figure 1 Effect of MME on LPS-induced $\mathrm{NO}$ and $\mathrm{PGE}_{2}$ production in BV-2 cells. BV-2 cells pretreated with different concentrations of MME for $2 \mathrm{~h}$ were stimulated with LPS $(1 \mathrm{\mu g} / \mathrm{mL})$ for $24 \mathrm{~h}$. The treated culture media were used to assay the amount of $\mathrm{NO}$ (A) and $\mathrm{PGE}_{2}$ production (B). BV-2 microglial cells were treated with various concentration of MME in the absence or presence of LPS $(1 \mu \mathrm{g} / \mathrm{mL})$. After $24 \mathrm{~h}$, cell viability was measured by MTS assay $(\mathbf{C})$. Data are presented as means $\pm \mathrm{SDs}$ of three independent experiments. ${ }^{a} p<0.05$ indicates significant differences compared to the non-treated group. ${ }^{b} p<0.05$ indicates significant differences compared to the LPS-only group. 


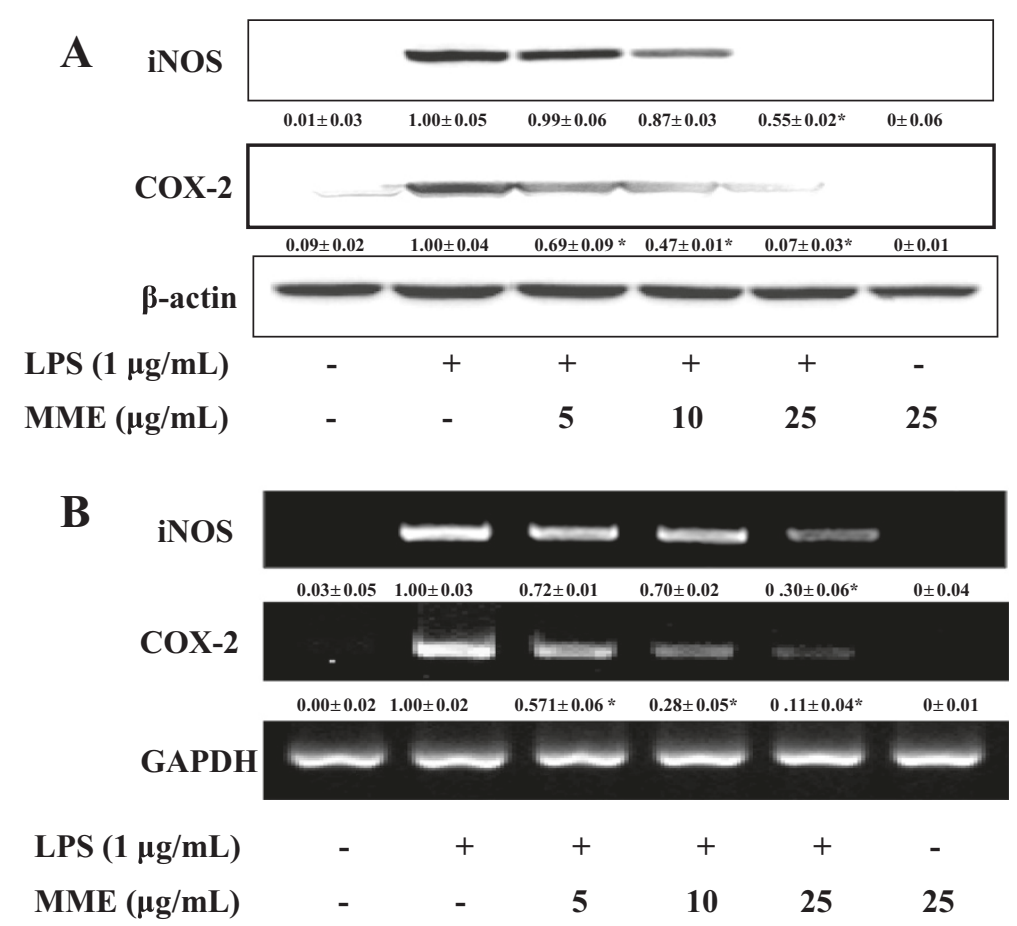

Figure 2 Effect of MME on LPS-induced iNOS and COX-2 expressions in LPS-stimulated BV-2 cells. (A) BV-2 cells were pretreated with different concentrations of MME for $2 \mathrm{~h}$ and stimulated with LPS $(1 \mu \mathrm{g} / \mathrm{mL})$ for $16 \mathrm{~h}$. The expression of iNOS, COX-2, and $\beta$-actin protein was detected by Western blot using corresponding antibodies. (B) Cells pretreated with various concentrations of MME for $2 \mathrm{~h}$ were stimulated with LPS $(1 \mu \mathrm{g} / \mathrm{mL})$ for $6 \mathrm{~h}$, and then total RNA was prepared for RT-PCR. The results presented are representative of three independent experiments. ${ }^{a} p<0.05$ indicates significant differences compared to the non-treated group. ${ }^{b} p<0.05$ indicates significant differences compared to the LPS-only group.

$\mathrm{NO}$ and $\mathrm{PGE}_{2}$ production is associated with downregulation of iNOS and COX-2 genes at transcriptional level.

\section{MME inhibits LPS-induced TNF- $\alpha$, IL- $1 \beta$, and IL- 6 secretion in BV-2 cells}

Since TNF- $\alpha$, IL- $1 \beta$, and IL- 6 are early secreted proinflammatory cytokines and their levels are up-regulated in a variety of acute and chronic inflammatory diseases, we measured the effects of MME on the production of these cytokines in LPS-stimulated BV-2 cells. To reach detectable ranges of secreted cytokines in cultured media, LPS stimulations were extended up to $24 \mathrm{~h}$. The stimulation of BV-2 cells with LPS induced remarkable increase in TNF- $\alpha$ (Figure 3A), IL-1 $\beta$ (Figure 3B), and IL-6 (Figure $3 C$ ). LPS-induced pro-inflammatory cytokines were significantly decreased by MME pretreatment in a dose-dependent manner $(p<0.05)$. The $\mathrm{EC}_{50}$ values of MME against TNF- $\alpha$, IL- $1 \beta$, and IL- 6 were estimated to be $11.8 \pm 1.2,7.55 \pm 0.5$, and $14.1 \pm 1.8 \mu \mathrm{g} / \mathrm{mL}$, respectively. These results indicate that MME effectively suppressed LPS-induced TNF- $\alpha$, IL-1 $\beta$, and IL- 6 production, indicating that MME inhibits the initial phase of the LPSstimulated inflammatory response.
MME inhibits degradation of IKB- $\alpha$ and translocation of NF-KB in LPS-stimulated BV-2 cells

To determine transcriptional control of MME, we investigated the effects of MME on the nuclear translocation of NF-kB/p65 subunit using LPS-stimulated BV-2 cells. Confocal microscopic observations revealed that NF-kB/ p65 was mainly located in the cytoplasm in unstimulated cells. After stimulation with LPS, most cytoplasmic p65 subunit was translocated into the nucleus, as shown in intense NF- $\mathrm{kB} / \mathrm{p} 65$ staining in the nucleus (Figure 4A). However, the level of NF-kB/p65 in the nucleus was markedly reduced by pretreatment with MME. Considering the inhibitory effects of MME on LPS-induced NF- $\mathrm{KB}$ translocation into nucleus, we next analyzed the inhibitory effect of MME on LPS-stimulated phosphorylation of IкB- $\alpha$ and the translocation of NF- $\kappa$ B by Western blot. LPS treatment induced IкB- $\alpha$ phosphorylation, responsible for the activation of NF- $\mathrm{kB}$, and MME pretreatment suppressed its phosphorylation and recovered the level of cytosolic ІкB- $\alpha$ in a dose-dependent manner (Figure 4B). As a result of IкB- $\alpha$ phosphorylation, the increased nuclear NF-kB level by LPS was reduced by MME pretreatment in a dose-dependent manner. Additionally, 

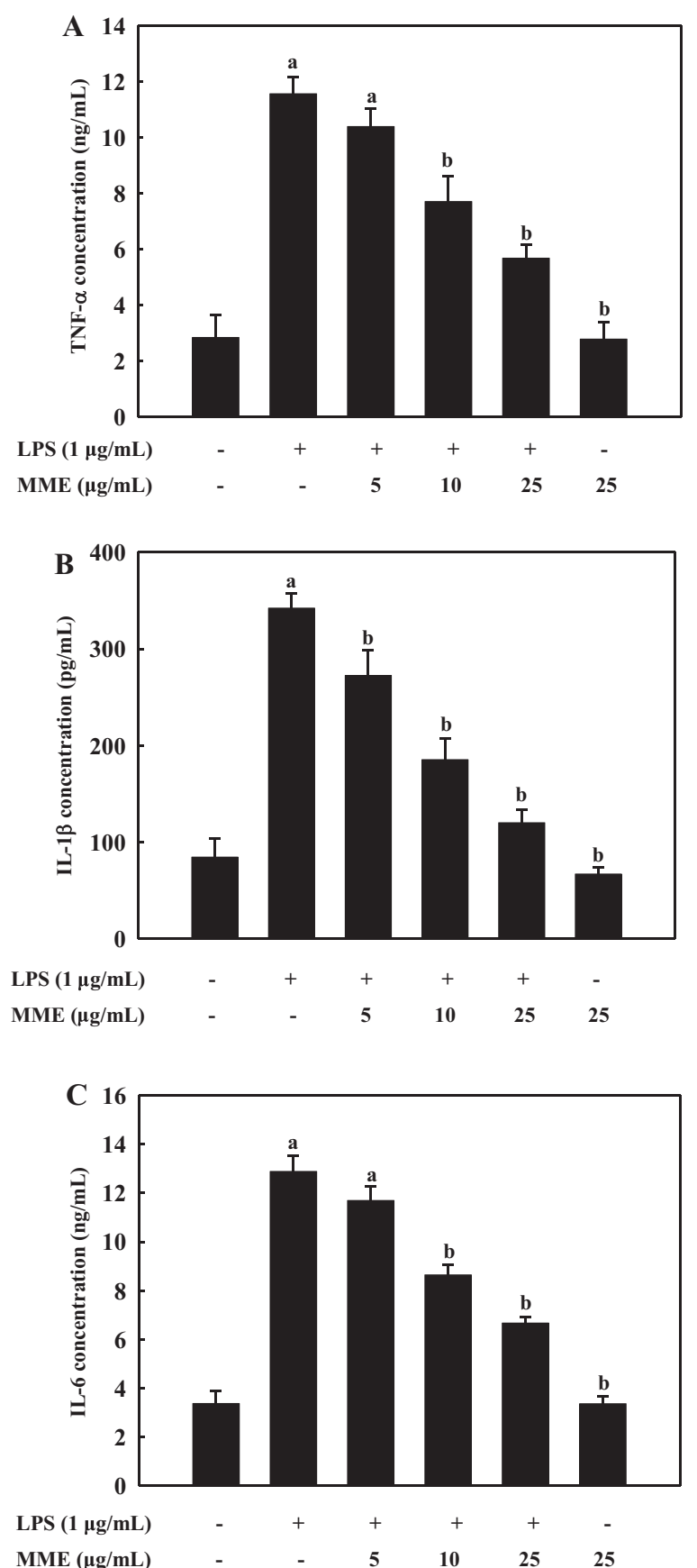

Figure 3 Effects of MME on the secretion of pro-inflammatory cytokines in LPS-stimulated BV-2 cells. BV-2 cells were treated with various concentrations of MME for $2 \mathrm{~h}$, and then stimulated with LPS $(1 \mu \mathrm{g} / \mathrm{mL})$ for $24 \mathrm{~h}$. TNF-a (A), IL-1 $\beta$ (B), and IL-6 (C) in the cultured media were measured by ELISA. Data are means \pm SDs of three independent experiments. ${ }^{a} p<0.05$ indicates significant differences compared to the non-treated group. ${ }^{b} p<0.05$ indicates significant differences compared to the LPS-only group.

we determined the effect of MME on the promoter activity of NF- $\mathrm{kB}$ in LPS-stimulated cells. The result suggests that MME pretreatment significantly inhibited LPS- induced NF- $\mathrm{kB}$ promoter activity of microglia in a dosedependent manner $(p<0.05$, Figure $4 C)$. These results indicate that the MME-mediated inhibition of iNOS, COX-2, and pro-inflammatory cytokine productions were regulated by the inhibition of NF- $\kappa B$ activation in LPS-stimulated BV-2 cells.

\section{MME inhibits activation of JNK $1 / 2$ and ERK $1 / 2$ in BV-2 cells}

To further investigate the molecular mechanisms of MME on the inhibition of NF- $\mathrm{KB}$ activation in LPSstimulated BV-2 cells, we measured the inhibitory effect of MME on the phosphorylation of MAPKs, which are associated with the regulation of NF- $\mathrm{KB}$ pathway. As shown in Figure 5A, MME inhibited phosphorylation of ERK $1 / 2$ and JNK1/2 in a dose-dependent manner in LPS-stimulated cells, whereas there was no marked effect on the phosphorylation of Akt in BV-2 cells. In addition, MME slightly reduced p38 MAPK phosphorylation compared with ERK1/2 and JNK1/2 phosphorylation. To further confirm the association of these signaling proteins with the MME's anti-inflammatory effect, we compared the production of $\mathrm{NO}$ and the protein levels of iNOS and COX-2 in the presence of MME, ERK inhibitor (PD98059) or JNK inhibitor (SP600125). As shown in Figure 5B, the levels of NO secretion from the LPS-stimulated BV-2 cells were remarkably inhibited by MME as well as by ERK or JNK inhibitors $(p<0.05)$. In addition, pretreatment with MME and SP600125 strongly inhibited LPS-induced NO production as well as iNOS and COX-2 production, whereas, pretreatment with PD98059 moderately inhibited the production of NO and inflammatory proteins. These results suggest that the additional characteristics of MME to regulated NF- $k B$ pathway via blocking the phosphorylation of ERK1/2 and JNK1/2 proteins in response to LPS.

\section{Isolation of anti-inflammatory compound from MME}

MME was further separated by reverse-phase column chromatography to identify anti-inflammatory activity (Figure 6). The peak indicated with sargachromenol showed a strong anti-inflammatory activity based on the inhibitory activity of NO production in LPS-treated BV-2 cells. The peak was collected by the repeated chromatographies and the chemical structure of the isolated compound was identified as sargachromenol from the comparison of its NMR spectra with the published spectral data. We obtained $4.5 \mathrm{mg}$ of sargachromenol from $1 \mathrm{~g}$ of MME. The purified sargachromenol showed high anti-inflammatory activity in LPS-stimulated BV-2 cells (Table 1, $\mathrm{EC}_{50}, 1.14 \pm 0.11 \mu \mathrm{g} / \mathrm{mL}$ ), indicating that sargachromenol is one of the major active compounds for antiinflammatory activity of MME. 


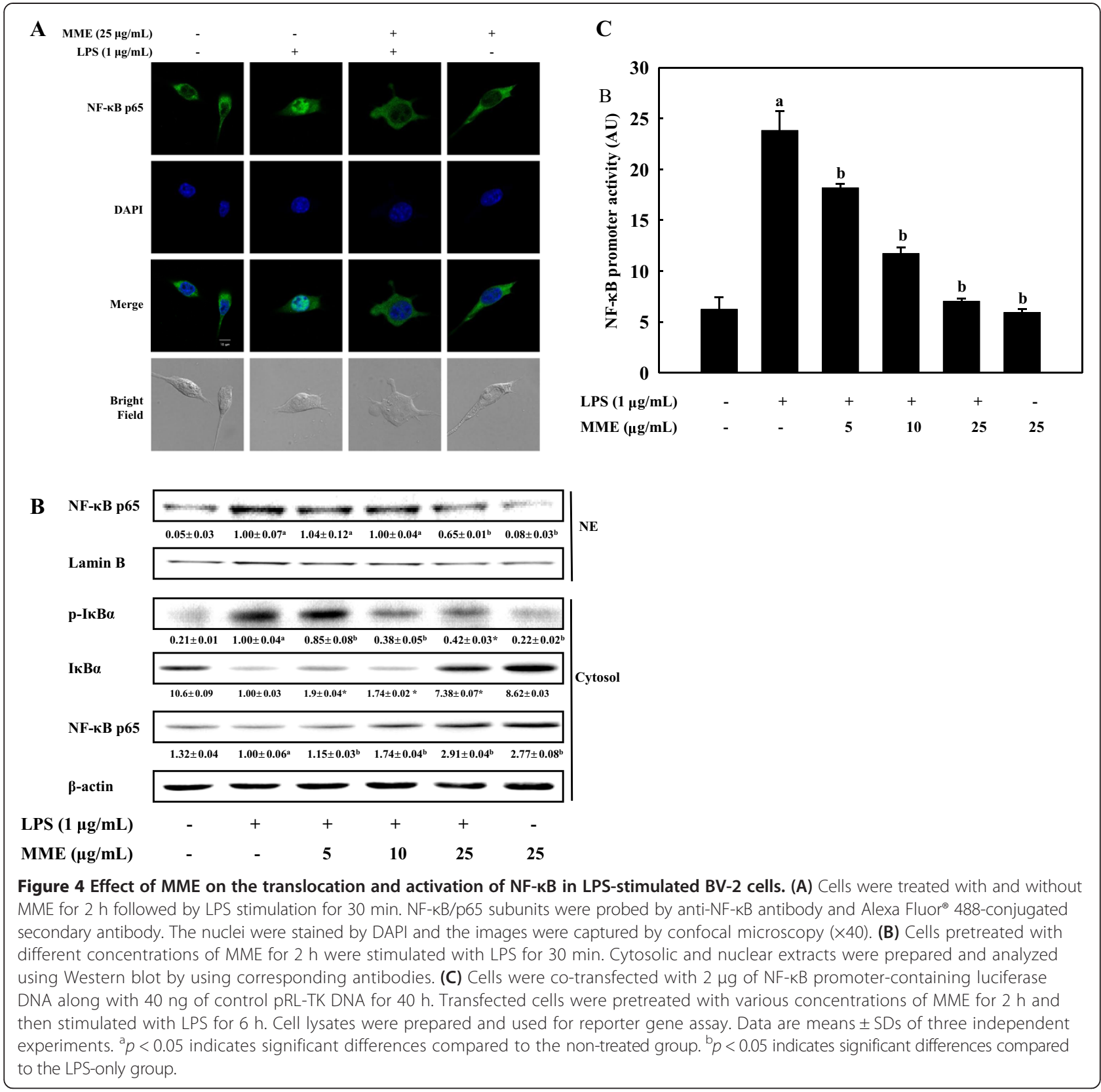

\section{Discussion}

Brown seaweeds and their extracts are a well-known sources of antioxidation or anti-inflammation due to their appreciable amount of polyphenols and pigments. Although significant differences were observed in both total polyphenolic contents and antioxidant activities of extracts from various species, high correlation was found between total polyphenolic contents and their antioxidant capacity to scavenge ROS [29]. Polyphenolic compounds from marine algae may prevent inflammatory disorders, cancer, and diabetes which are associated with the regulation of free radicals generated in the cells [30,31]. In this regard, we analyzed antioxidant and anti-inflammatory activities of five representative brown algae along the southeastern coast of Korea. Among them, M. myagroides showed the highest phenolic contents and ROS scavenging activity as well as anti-inflammatory activity. High phenolic content in $M$. myagroides may participate in the inhibition of NO production in LPS-treated BV-2 cells. As anti-inflammatory activities from $M$. myagroides, fucoxanthin [32], fatty acid [33], 6,6-bieckol [22], and phlorofucofuroeckol B [21] have shown potent activities in macrophage or microglial cells. However, anti-inflammatory activity of MME in this study may not be due to fucoxanthin, fatty acid or phlorotannins, since the peaks of those compounds were not detected in the chromatogram 


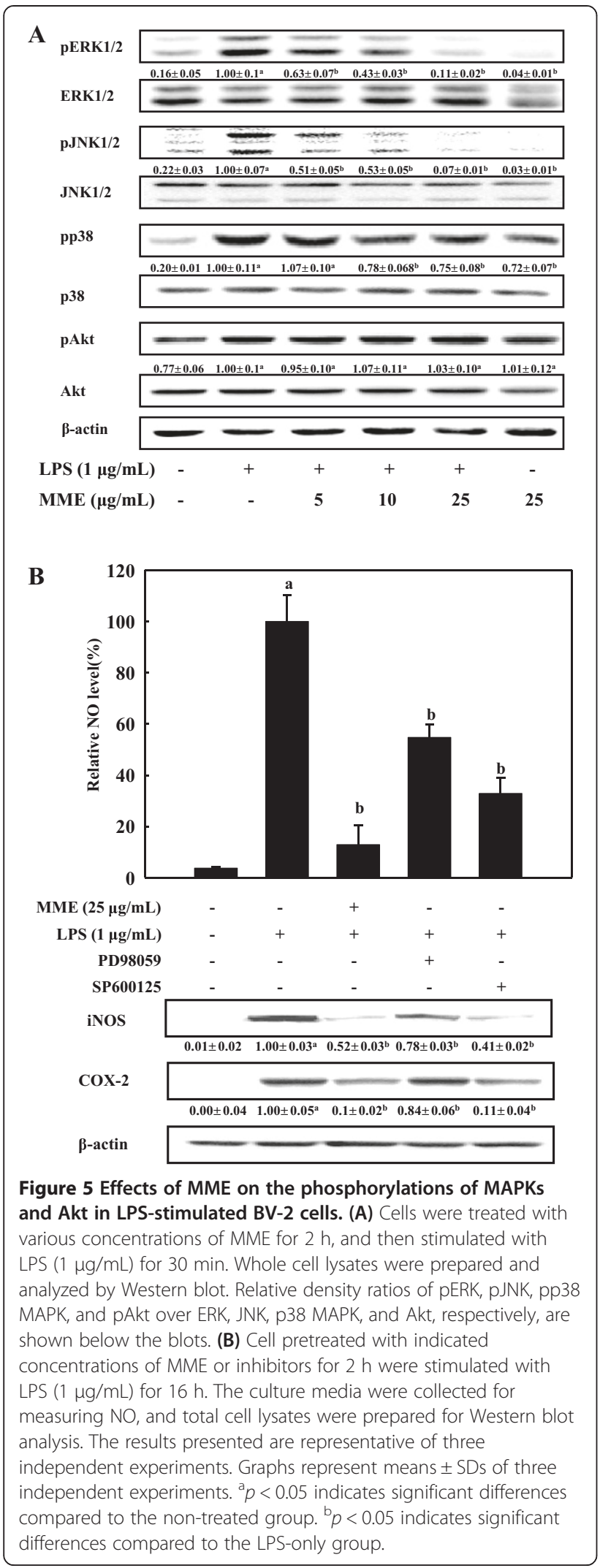

(Figure 6) $[20,21]$. Thus, we hypothesized strong antiinflammatory compounds are contained in MME and we separated the components from MME using $\mathrm{C}_{18}$ column and isolated sargachromenol having strong anti-inflammatory activity (Table 1). Base on the inhibitory activity of NO production in LPS-stimulated BV-2 cells, sargachromenol might be a main antiinflammatory compound in MME.

$\mathrm{NO}$ and $\mathrm{PGE}_{2}$ are crucial inflammatory and neurotoxic mediators. These inflammatory mediators are responsible for the harmful effects on brain diseases, including ischemia, Alzheimer's disease, and neuronal death [34]. In vitro and in vivo studies have revealed that overproductions of $\mathrm{NO}$ and $\mathrm{PGE}_{2}$ by enhanced $\mathrm{iNOS}$ and COX-2 protein levels, are associated with central nervous injuries and diseases [6]. iNOS and COX-2 proteins have been over-expressed in microglial cells from the rodent brain treated with LPS [2]. In addition, iNOS and COX-2 inhibitors provide neuroprotective effects against LPS-induced neurotoxicity, suggesting $\mathrm{NO}$ and $\mathrm{PGE}_{2}$ have important roles in neurotoxicity $[6,35]$. In this regard, inhibition of inflammatory mediator production is considered as a key step in the control of neuroinflammatory diseases. In the present study, we demonstrated that MME inhibited productions of both $\mathrm{NO}$ and $\mathrm{PGE}_{2}$ in LPS-stimulated BV-2 cells (Figure 1). Moreover, we provide evidence that MME-mediated inhibition of $\mathrm{NO}$ and $\mathrm{PGE}_{2}$ production was the consequence of the suppression of both mRNA and protein levels of iNOS and COX-2 in LPS-stimulated BV-2 cells (Figure 2). Furthermore, we found that the suppression of COX-2 mRNA expression by MME was more marked than that of COX-2 protein in BV-2 cells, indicating that inhibition of $\mathrm{PGE}_{2}$ by MME is associated with downregulation of COX-2 at both transcriptional and translational levels in LPS-stimulated BV-2 cells. Thus, the present findings may address that MME has protective effects on neurodegenerative diseases induced by neuroinflammation.

Pro-inflammatory cytokines, including TNF- $\alpha$, IL-1 $\beta$, and IL-6 are small secreted proteins that regulate immunity and inflammation. Their production is increased in inflammatory states and they function by regulating the intensity and duration of the immune response [3]. TNF- $\alpha$ plays a central role in initiating and regulating the cytokine signaling cascade during an inflammatory response in neuronal cells. In inflammatory disease states, TNF- $\alpha$ along with other pro-inflammatory mediators and neurotoxic substances is predominantly produced by activated microglia [4]. IL-1 $\beta$ is an important initiator of the immune response, playing a key role in the onset and development of a complex hormonal and cellular inflammatory cascade. IL-6 is a multifunctional cytokine that plays an important role in host defense, with major regulatory effects upon the inflammatory response [36]. Excessive 


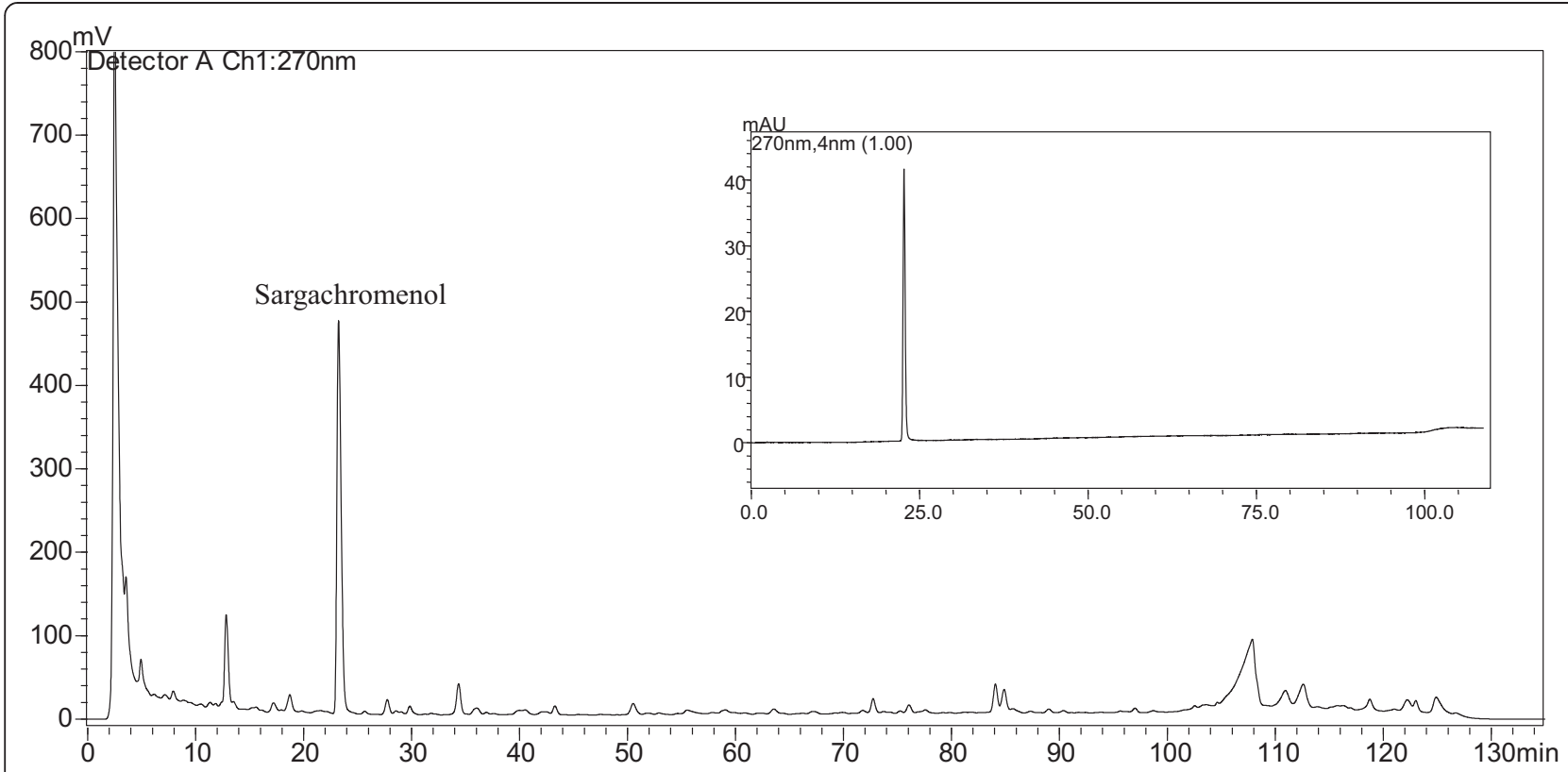

Figure 6 Representative HPLC chromatogram of MME. Aliquots of MME were separated by HPLC system and peak was identified by comparison of retention time to the corresponding authentic standard (inlet).

productions of these pro-inflammatory cytokines activate microglia and lead to neural cell deaths, resulting in the pathogenesis of several neurological and neurodegenerative disorders $[4,6,37]$. As an alternative chemoprevention of inflammatory diseases, natural compounds able to inhibit the production of pro-inflammatory cytokines may be attractive as anti-inflammatory agents and, for this reason, the inhibitory effects of phytochemicals on the production of pro-inflammatory cytokines have been intensively studied to develop anti-inflammatory agents for preventing inflammatory diseases [38]. In the present study, we have demonstrated that MME remarkably suppressed the secretions of TNF- $\alpha$, IL-1 $\beta$, and IL- 6 in LPS-stimulated BV-2 cells (Figure 3). Thus, the present findings may further support the potential of MME as a neuroprotective by reducing inflammation.

NF-KB plays an important role in the regulation of cell survival and coordinates the expression of pro-inflammatory proteins and cytokines, including iNOS, COX-2, TNF- $\alpha$, IL- $1 \beta$, and IL-6 [8]. NF- $\kappa B$ is present as an inactive complex associated with an inhibitory subunit, ІкB- $\alpha$, in cytoplasm. Activation of NF-kB caused by LPS or pro-inflammatory cytokines leads to degradation of IкB- $\alpha$ and inducing translocation of NF-kB into nucleus [12]. Recently, we demonstrated that extract of brown algae including Saccharina japonica [19,20], M. myagroides [21,22], Ecklonia stolonifera [15], and Sargassum fulvellum [39] inhibited the activation of NF-kB signaling pathway through the blockade of proteolytic degradation of IкB- $\alpha$. In this study, we observed that enhanced phosphorylation of IKB- $\alpha$ by LPS was reduced by MME treatment, suggesting that MME protected the proteolytic degradation of IkB- $\alpha$ (Figure 4B). Degradation of IкB- $\alpha$ involves its dissociation from the inactive complex, leading to activation of NF- $\mathrm{kB}$ in response to LPS, which is demonstrated by NF- $\mathrm{kB}$ promoter activity (Figure $4 \mathrm{C}$ ). Moreover, the nuclear translocation of NF- $\mathrm{KB}$ was significantly inhibited by MME, supporting the inhibition of NF- $\kappa B$ activation by MME (Figure 4A). From these data, the MME-mediated down-expression of LPS-induced inflammatory mediators and cytokines in BV-2 cells is partially associated with the ability of MME to inhibit the IкB/NF-кB signaling pathway.

$\mathrm{NF}-\mathrm{kB}$ activation is alternatively regulated by various cellular kinases including MAPKs and Akt, which are the groups of protein kinases to play key roles in inflammatory reactions $[38,40]$. MAPKs are involved in inflammatory signaling cascades and regulation of iNOS and COX-2 through the activation of NF-kB in LPS-stimulated immune cells $[9,12,38]$. Therefore, anti-inflammatory mechanisms are closely related to inhibition of MAPKs in stimulated BV-2 cells. In this study, we have specifically shown that MME inhibits the activation of ERKs and JNKs, but not Akt and little p38 MAPK, in response to LPS in BV-2 cells, suggesting that ERKs and JNKs are additional targets of MME. Although, hexane fraction of MME down-regulated the phosphorylation of MAPKs and Akt in LPS-stimulated RAW 264.7 cells [22], it is hard to conclude why MME did not inhibit the phosphorylation of p38 MAPK and Akt in LPS-stimulated BV-2 cells. To further confirm the involvement of ERK1/2 and JNK1/2 on the activation of NF- $\mathrm{KB}$, $\mathrm{NO}$ production and iNOS and COX-2 expression were 
determined. The inhibitory level of NO production showed $45 \%$ in the PD98059 treated cells and 65\% in the SP600125 treated cells. MME treatment showed higher inhibitory effect of NO production than both inhibitors, which indicates that MME inhibits both phosphorylation of ERK1/2 and JNK1/2 (Figure 5B). In addition, treatment of both inhibitors resulted in suppression of iNOS and COX-2 expressions. Considering roles of MAPKs in inflammatory gene expression, MME inhibited, at least in part, LPS-induced NF- $\mathrm{kB}$ activation in the microglial cells by inhibiting the JNK and ERK pathways.

\section{Conclusions}

We have demonstrated that sargachromenol-rich MME inhibits the production of $\mathrm{NO}, \mathrm{PGE}_{2}$, and pro-inflammatory cytokines as well as iNOS and COX-2 at transcriptional and translational levels. Anti-inflammatory action of MME on LPS-stimulated BV-2 cells was associated with blocking ІкB/ NF-kB, JNK, and ERK pathways. Verification and confirmation of its anti-inflammatory activity and relative mechanism at the cellular and molecular levels will be beneficial for the further application of MME in therapeutic agents for neuroinflammation in neurodegenerative diseases. Future studies will be necessary in order to determine the bioavailability of this preparation and metabolites in animal tissue.

\section{Competing interests}

The authors declare that they have no competing interests.

\section{Authors' contributions}

SK carried out the main experiment and wrote the manuscript. MSL prepared MME and performed partial Western blotting. BL contributed to discuss and write the manuscript. EJJ performed immunocytochemistry. WGG assisted ELISA for measuring the proinflammatory cytokines. EJJ and WGG also assisted isolated and identified sargachromenol from MME. NYY collected M. myogroides. HRK designed and organized this study. All authors read and approved the final version of the manuscript.

\section{Acknowledgments}

This work was financially supported by National Fisheries Research and Development Institute, Republic of Korea (RP-2013-FS-000). Authors appreciate the Marine Brown Algae Resources Bank for the deposition and identification of the samples.

\section{Author details \\ ${ }^{1}$ Department of Food Science and Nutrition, Pukyong National University, Yongso-ro, Nam-gu, Busan 608-737, South Korea. ${ }^{2}$ National Institute of Child Health and Human Development, National Institutes of Health, Bethesda, MD 20892, USA. ${ }^{3}$ Food and Safety Research Division, National Fisheries Research and Development Institute, 216, Gijanghaean-ro, Gijang-eup, Gijang-gun, Busan 619-705, South Korea. ${ }^{4}$ Institute of Fisheries Sciences, Pukyong National University, Ilgwang-ro, Ilgwang-myeon, Gijang-gun, Busan 619-911, South Korea.}

Received: 3 October 2013 Accepted: 1 July 2014

Published: 9 July 2014

\section{References}

1. Bonaiuto C, McDonald PP, Rossi F, Cassatella MA: Activation of nuclear factor- $\mathrm{KB}$ by $\beta$-amyloid peptides and interferon- $\gamma$ in murine microglia. J Neuroimmunol 1997, 77:51-56.
2. Qin L, Li G, Qian X, Liu Y, Wu X, Liu B, Hong JS, Block ML: Interactive role of the toll-like receptor 4 and reactive oxygen species in LPS-induced microglia activation. Glia 2005, 52:78-84.

3. Bianchi R, Giambanco I, Donato R: S100B/RAGE-dependent activation of microglia via NF- KB and AP-1 Co-regulation of COX-2 expression by S100B, IL-1 $\beta$ and TNF-a. Neurobiol Aging 2010, 31:665-677.

4. Dheen ST, Kaur C, Ling EA: Microglial activation and its implications in the brain diseases. Curr Med Chem 2007, 14:1189-1197.

5. Gonzalez-Scarano F, Baltuch G: Microglia as mediators of inflammatory and degenerative diseases. Annu Rev Neurosci 1999, 22:219-240.

6. Teismann P, Tieu K, Cohen O, Choi DK, Wu DC, Marks D, Vila M, Jackson-Lewis V, Przedborski S: Pathogenic role of glial cells in Parkinson's disease. MovDisord 2003, 18:121-129.

7. D'Acquisto F, luvone T, Rombola L, Sautebin L, Di Rosa M, Carnuccio R: Involvement of NF-KB in the regulation of cyclooxygenase-2 protein expression in LPS-stimulated J774 macrophages. FEBS Lett 1997, 418:175-178.

8. Marks-Konczalik J, Chu SC, Moss J: Cytokine-mediated transcriptional induction of the human inducible nitric oxide synthase gene requires both activator protein 1 and nuclear factor $\mathrm{KB}$-binding sites. J Biol Chem 1998, 273:22201-22208.

9. Kim AR, Lee MS, Shin TS, Hua H, Jang BC, Choi JS, Byun DS, Utsuki T, Ingram D, Kim HR: Phlorofucofuroeckol A inhibits the LPS-stimulated iNOS and COX-2 expressions in macrophages via inhibition of NF-KB, Akt, and p38 MAPK. Toxicol In Vitro 2011, 25:1789-1795.

10. Makarov SS: NF-KB in rheumatoid arthritis: a pivotal regulator of inflammation, hyperplasia, and tissue destruction. Arthritis Res 2001, 3:200-206.

11. Janssen-Heininger YM, Poynter ME, Baeuerle PA: Recent advances towards understanding redox mechanisms in the activation of nuclear factor $\mathrm{KB}$. Free Radic Biol Med 2000, 28:1317-1327.

12. Zeng KW, Wang S, Dong X, Jiang Y, Tu PF: Sesquiterpene dimer (DSF-52) from Artemisia argyi inhibits microglia-mediated neuroinflammation via suppression of NF-KB, JNK/p38 MAPKs and Jak2/Stat3 signaling pathways. Phytomedicine 2014, 21:298-306.

13. Herlaar E, Brown Z: p38 MAPK signalling cascades in inflammatory disease. Mol Med Today 1999, 5:439-447.

14. Kim AR, Shin TS, Lee MS, Park JY, Park KE, Yoon NY, Kim JS, Choi JS, Jang BC, Byun DS, Park NK, Kim HR: Isolation and identification of phlorotannins from Ecklonia stolonifera with antioxidant and anti-inflammatory properties. J Agric Food Chem 2009, 57:3483-3489.

15. Lee MS, Kwon MS, Choi JW, Shin T, No HK, Choi JS, Byun DS, Kim JI, Kim HR: Anti-inflammatory activities of an ethanol extract of Ecklonia stolonifera in lipopolysaccharide-stimulated RAW 264.7 murine macrophage cells. J Agric Food Chem 2012, 60:9120-9129.

16. Lee MS, Shin T, Utsuki T, Choi JS, Byun DS, Kim HR: Isolation and identification of phlorotannins from Ecklonia stolonifera with antioxidant and hepatoprotective properties in tacrine-treated HepG2 cells. J Agric Food Chem 2012, 60:5340-5349.

17. Kang JY, Khan MN, Park NH, Cho JY, Lee MC, Fujii H, Hong YK: Antipyretic, analgesic, and anti-inflammatory activities of the seaweed Sargassum fulvellum and Sargassum thunbergii in mice. J Ethnopharmacol 2008, 116:187-190.

18. Khan MN, Lee MC, Kang JY, Park NG, Fujii H, Hong YK: Effects of the brown seaweed Undaria pinnatifida on erythematous inflammation assessed using digital photo analysis. Phytother Res 2008, 22:634-639.

19. Lee HS, Ryu DS, Lee GS, Lee DS: Anti-inflammatory effects of dichloromethane fraction from Orostachysjaponicus in RAW 264.7 cells: suppression of NF-KB activation and MAPK signaling. J Ethnopharmacol 2012, $140: 271-276$

20. Lee JY, Lee MS, Choi HJ, Choi JW, Shin T, Woo HC, Kim JI, Kim HR: Hexane fraction from Laminaria japonica exerts anti-inflammatory effects on lipopolysaccharide-stimulated RAW 264.7 macrophages via inhibiting NF-kappaB pathway. Eur J Nutr 2013, 52:409-421.

21. Joung EJ, Lee MS, Choi JW, Kim JS, Shin T, Jung BM, Kim JI, Kim HR: Anti-inflammatory effects of phlorofucofuroeckol B-rich ethyl acetate fraction obtained from Myagropsis myagroides on lipopolysaccharidestimulated RAW 264.7 cells and mouse edema. Int Immunopharmacol 2012. 14:471-480.

22. Joung EJ, Lee MS, Choi JW, Kim JS, Shin T, Jung BM, Yoon NY, Lim CW, Kim Jl, Kim HR: Anti-inflammatory effect of ethanolic extract from Myagropsis myagroides on murine macrophages and mouse ear edema. BMC Complement Altern Med 2012, 12:171. 
23. Kim JA, Ahn BN, Kong CS, Kim SK: Protective effect of chromene isolated from Sargassum horneri against UV-A-induced damage in skin dermal fibroblasts. Exp Dermatol 2012, 21:630-631.

24. Choi BW, Ryu G, Park SH, Kim ES, Shin J, Roh SS, Shin HC, Lee BH: Anticholinesterase activity of plastoquinones from Sargassum sagamianum: lead compounds for Alzheimer's disease therapy. Phytother Res 2007, 21:423-426.

25. Tsang CK, Ina A, Goto T, Kamei Y: Sargachromenol, a novel nerve growth factor-potentiating substance isolated from Sargassum macrocarpum, promotes neurite outgrowth and survival via distinct signaling pathways in PC12D cells. Neuroscience 2005, 132:633-643.

26. Henn A, Lund S, Hedtjarn M, Schrattenholz A, Porzgen P, Leist M: The suitability of BV2 cells as alternative model system for primary microglia cultures or for animal experiments examining brain inflammation. ALTEX 2009, 26:83-94.

27. Jayasooriya RG, Lee KT, Lee HJ, Choi YH, Jeong JW, Kim GY: Anti-inflammatory effects of beta-hydroxyisovalerylshikonin in BV2 microglia are mediated through suppression of the PI3K/Akt/NF-KB pathway and activation of the Nrf2/HO-1 pathway. Food Chem Toxicol 2014, 65:82-89.

28. Koivikko R, Loponen J, Honkanen T, Jormalainen V: Contents of soluble, cell-wall-bound and exuded phlorotannins in the brown alga Fucus vesiculosus, with implications on their ecological functions. J Chem Ecol 2005, 31:195-212.

29. Wang T, Jónsdóttir R, Ólafsdóttir G: Total phenolic compounds, radical scavenging and metal chelation of extracts from Icelandic seaweeds. Food Chem 2009, 116:240-248.

30. Conner EM, Grisham MB: Inflammation, free radicals, and antioxidants. Nutrition 1996, 12:274-277.

31. Haslam E: Natural polyphenols (vegetable tannins) as drugs: possible modes of action. J Nat Prod 1996, 59:205-215.

32. Heo SJ, Yoon WJ, Kim KN, Ahn GN, Kang SM, Kang DH, Affan A, Oh C, Jung WK, Jeon YJ: Evaluation of anti-inflammatory effect of fucoxanthin isolated from brown algae in lipopolysaccharide-stimulated RAW 264.7 macrophages. Food Chem Toxicol 2010, 48:2045-2051.

33. Kim S, Kim JI, Choi JW, Kim M, Yoon NY, Choi CG, Choi JS, Kim HR: Anti-inflammatory effect of hexane fraction from Myagropsis myagroides ethanolic extract in lipopolysaccharide-stimulated BV-2 microglial cells. J Pharm Pharmacol 2013, 65:895-906.

34. Meda L, Cassatella MA, Szendrei Gl, Otvos L Jr, Baron P, Villalba M, Ferrari D, Rossi F: Activation of microglial cells by $\beta$-amyloid protein and interferon- $\gamma$. Nature 1995, 374:647-650.

35. Oh YT, Lee JY, Lee J, Kim H, Yoon KS, Choe W, Kang I: Oleic acid reduces lipopolysaccharide-induced expression of iNOS and COX-2 in BV2 murine microglial cells: possible involvement of reactive oxygen species, p38 MAPK, and IKK/NF-KB signaling pathways. Neurosci Lett 2009, 464:93-97.

36. Raivich G, Bohatschek M, Kloss CU, Werner A, Jones LL, Kreutzberg GW Neuroglial activation repertoire in the injured brain: graded response, molecular mechanisms and cues to physiological function. Brain Res Brain Res Rev 1999, 30:77-105.

37. Pahan K, Sheikh FG, Liu X, Hilger S, McKinney M, Petro TM: Induction of nitric- oxide synthase and activation of NF-KB by interleukin-12 p40 in microglial cells. J Biol Chem 2001, 276:7899-7905.

38. Kim AR, Lee MS, Choi JW, Utsuki T, Kim Jl, Jang BC, Kim HR: Phlorofucofuroeckol A suppresses expression of inducible nitric oxide synthase, cyclooxygenase-2, and pro-inflammatory cytokines via inhibition of nuclear factor-kB, c-Jun $\mathrm{NH}_{2}$-terminal kinases, and Akt in microglial cells. Inflammation 2013, 36:259-271.

39. Gwon WG, Lee MS, Kim JS, Kim JI, Lim CW, Kim NG, Kim HR: Hexane fraction from Sargassum fulvellum inhibits lipopolysaccharide-induced inducible nitric oxide synthase expression in RAW 264.7 cells via NF-KB pathways. Am J Chin Med 2013, 41:565-584.

40. Chen Z, Hagler J, Palombella VJ, Melandri F, Scherer D, Ballard D, Maniatis T: Signal-induced site-specific phosphorylation targets IkBa to the ubiquitin-proteasome pathway. Genes Dev 1995, 9:1586-1597.

doi:10.1186/1472-6882-14-231

Cite this article as: Kim et al:: Anti-inflammatory effects of sargachromenol-rich ethanolic extract of Myagropsis myagroides on lipopolysaccharide-stimulated BV-2 cells. BMC Complementary and Alternative Medicine 2014 14:231.

\section{Submit your next manuscript to BioMed Central and take full advantage of:}

- Convenient online submission

- Thorough peer review

- No space constraints or color figure charges

- Immediate publication on acceptance

- Inclusion in PubMed, CAS, Scopus and Google Scholar

- Research which is freely available for redistribution 